High-confinement SiGe low-loss waveguides for Si-based optoelectronics

S. P. Pogossian, L. Vescan, and A. Vonsovici

Citation: Appl. Phys. Lett. 75, 1440 (1999);

View online: https://doi.org/10.1063/1.124719

View Table of Contents: http://aip.scitation.org/toc/apl/75/10

Published by the American Institute of Physics

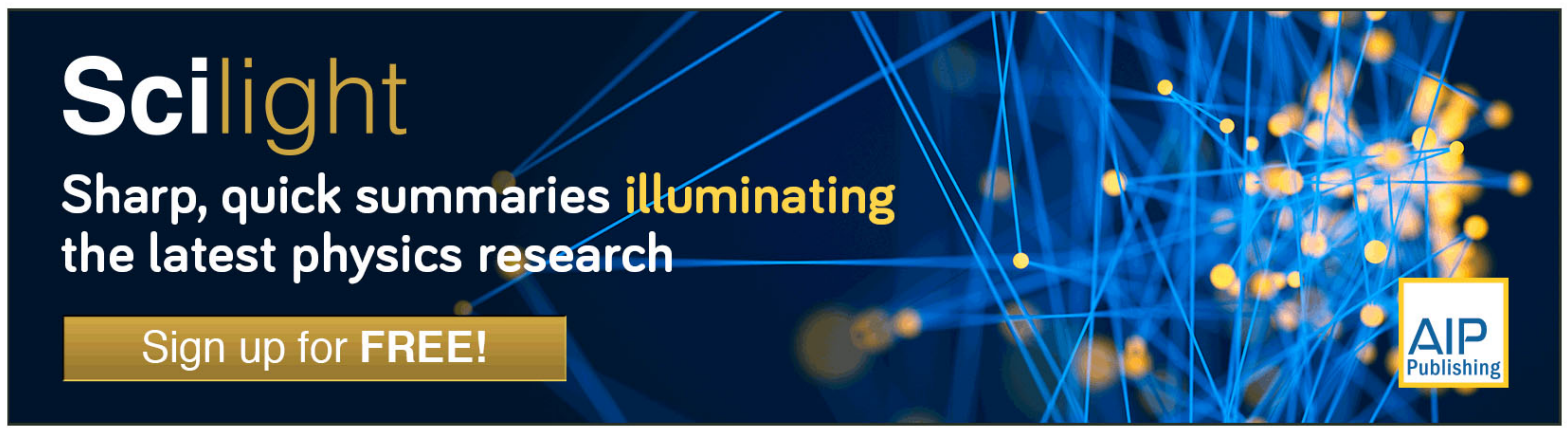




\title{
High-confinement SiGe low-loss waveguides for Si-based optoelectronics
}

\author{
S. P. Pogossian ${ }^{\text {a) }}$ \\ Institut für Schicht and Ionentechnik (ISI), Forschungszentrum Jülich GmbH, D-52425 Jülich, Germany \\ and Laboratoire de Magnétisme de Bretagne, CNRS/UPRESA 6135, Université de Bretagne Occidentale, \\ UFR Sciences et Techniques, Brest Cedex 29285, France \\ L. Vescan \\ Institut für Schicht and Ionentechnik (ISI), Forschungszentrum Jülich GmbH, D-52425 Jülich, Germany
}

\author{
A. Vonsovici \\ School of Electronics, Information Technology and Mathematics, University of Surrey, Guildford GU2 5XH, \\ United Kingdom
}

(Received 15 April 1999; accepted for publication 7 July 1999)

\begin{abstract}
The realization of two-dimensional $\mathrm{SiGe} / \mathrm{Si}$ strained-layer low-loss waveguide $(1.7 \mathrm{db} / \mathrm{cm})$ is reported. The waveguide geometry is grown by selective epitaxy. It ensures loosened cutoff and critical thickness conditions. This geometry could be applied for waveguide active devices like light emitting diodes, photodetectors, or modulators. Because of the high cross section of the guided mode, these devices could be easily interfaced with optical fibers. (C) 1999 American Institute of Physics. [S0003-6951(99)03035-1]
\end{abstract}

The recent interest in SiGe optoelectronic devices is because of the possibility of integration of optical and high speed electronic functions on a Si substrate. ${ }^{1,2} \mathrm{SiGe}$ is a suitable alloy for optoelectronic applications owing to a relatively high absorption on fiber communications wavelengths. Thus, poor optical properties of $\mathrm{Si}$ can be counterbalanced by employing $\mathrm{SiGe}$ components. SiGe optoelectronic devices are appealing since they offer a tuneable band gap from 1.1 to $1.5 \mu \mathrm{m}$ by varying the Ge content in the alloy or by controlling the strain state. That opens a large field of research activities with device applications such as roomtemperature operating light emitting diodes (LEDs), ${ }^{3}$ photodetectors, ${ }^{4}$ modulators, ${ }^{5,6}$ guided wave demultiplexers, ${ }^{7}$ etc. The main design parameter for these devices is the confinement factor in the active SiGe layer. Until now this was practically limited by the critical thickness of SiGe alloys that can be grown on a Si substrate without plastic relaxation. Recent advances in selective epitaxy ${ }^{8-11}$ permit us to circumvent this problem and to achieve higher confinement factors.

Several kinds of SiGe waveguides were obtained by different authors. ${ }^{12-19}$ There are two main obstacles for the realization of single mode strained-layer waveguides with high Ge concentration. The first is related to the cutoff thickness limitation in asymmetrical SiGe waveguides. ${ }^{13}$ Because of the refractive index asymmetry only a limited quantity of Ge can be incorporated into these waveguides for single mode operation. ${ }^{20}$ In Refs. 19 and 21 this obstacle was withdrawn by deposing a thick $\mathrm{Si}$ cap layer on the $\mathrm{Si}_{1-x} \mathrm{Ge}_{x}$, which makes the structure closer to a symmetric configuration $\mathrm{Si} / \mathrm{Si}_{1-x} \mathrm{Ge}_{x} / \mathrm{Si}$ with respect to the refractive index and therefore the cutoff limitation is loosened. However, there is a second limitation due to the critical thickness for plastic relaxation of $\mathrm{Si}_{1-x} \mathrm{Ge}_{x} / \mathrm{Si}$ which limits the confinement factor in this region.

${ }^{a)}$ Electronic mail: pogossia@univ-brest.fr
An interesting solution of the critical thickness limitation was proposed by our group. In that approach, SiGe strained layers are realized by selective epitaxy on patterned substrates. ${ }^{8,22}$ We use this idea for the realization of $\mathrm{SiGe}$ waveguides with higher confinement factors and lower cutoff thickness restrictions. The solution is presented in Fig. 1. The main difference from other methods is the local deposition of the $\mathrm{SiGe}$ in a finite stripe region while in the conventional Rib or Ridge geometry the SiGe layer is deposited on an entire wafer and afterwards patterned by reactive ion etching.

In order to show the influence of $\mathrm{Si}$ and $\mathrm{SiGe}$ cap layers on the confinement of the light in the SiGe guiding film, we have carried out calculations by the spectral index (SI) method $^{23}$ in a previous paper. ${ }^{22}$ Namely, we have investigated the cutoff condition dependence of cap layers thickness versus the thickness of the $\mathrm{Si}_{0.8} \mathrm{Ge}_{0.2}$ guiding film by using the SI method. Our calculations show that a cap layer of about $1 \mu \mathrm{m}$ thickness is sufficient for the realization of strained $\mathrm{Si}_{0.8} \mathrm{G}_{0.2} / \mathrm{Si}$ waveguides. Very thick cap layers are

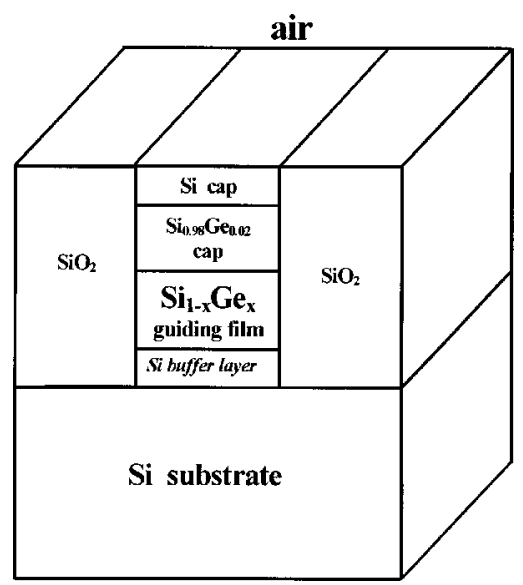

FIG. 1. Symmetric stripe SiGe two-dimensional waveguide on Si substrate after selective epitaxy. The $\mathrm{SiO}_{2}$ is removed afterwards. 
TABLE I. Parameters of SiGe waveguides grown by selective epitaxy.

\begin{tabular}{cccccc}
\hline \hline & $\begin{array}{c}\text { Si buffer } \\
\text { layer } \\
(\mathrm{nm})\end{array}$ & $\begin{array}{c}\mathrm{Si}_{1-x} \mathrm{Ge}_{x} \\
\text { guiding film } \\
\text { thickness } \\
(\mathrm{nm})\end{array}$ & $\begin{array}{c}\mathrm{Ge} \text { content } x{\text { in } \mathrm{Si}_{1-x} \mathrm{Ge}_{x}}_{\text {guiding film }} \\
\text { Sample }\end{array}$ & $\begin{array}{c}\text { First } \\
\mathrm{Si}_{0.98} \mathrm{Ge}_{0.02} \\
\text { cap layer } \\
(\mathrm{nm})\end{array}$ & $\begin{array}{c}\text { Second } \\
\mathrm{Si} \text { cap layer } \\
(\mathrm{nm})\end{array}$ \\
\hline 1427 & 150 & 380 & 0.20 & 625 & 2 \\
1430 & 150 & 320 & 0.19 & 630 & 2 \\
\hline \hline
\end{tabular}

not necessary since there is always a residual cutoff limitation independent of cap thickness. ${ }^{22}$ Our strained SiGe waveguide geometry is therefore less critical with respect to the critical thickness compared to those grown on a wafer scale.

The sequence of epitaxial growth starts with the Si substrate patterning using $\mathrm{SiO}_{2}$. Next, a Si buffer layer is deposited by selective epitaxy ${ }^{8-11}$ prior to the SiGe growth. Then the $\mathrm{Si}_{1-x} \mathrm{Ge}_{x}$ guiding film is deposited and afterwards covered first by a $\mathrm{Si}_{0.98} \mathrm{Ge}_{0.02}$ cap layer and then by a $\mathrm{Si}$ cap layer. Cap layers allow us to make the waveguide closer to a symmetric waveguide geometry.

The selective epitaxy was performed in a low pressure chemical vapor deposition system, which is a high vacuum, horizontal, cold wall reactor with radiation heating. ${ }^{8-11}$ $\mathrm{Si}(001)$ wafers ( $n$ type, $1 \Omega \mathrm{cm}$ ) were thermally oxidized and patterned with stripes $1 \mathrm{~cm}$ long and different widths. The epitaxy was performed at a temperature of $700{ }^{\circ} \mathrm{C}$ at 0.1 Torr pressure. Layer thickness and composition of the $\mathrm{Si}_{1-x} \mathrm{Ge}_{x}$ layers were determined by Rutherford backscattering spectrometry. Surface morphology studies were performed by scanning electron microscope and by a DI Nanoscope IIIa atomic force microscope in tapping mode. The layer sequence for the $\mathrm{Si}_{1-x} \mathrm{Ge}_{x}$ waveguides is shown in Table I. Waveguide insertion loss measurements for $\mathrm{Si} / \mathrm{Si}_{0.98} \mathrm{Ge}_{0.02} / \mathrm{Si}_{1-x} \mathrm{Ge}_{x} / \mathrm{Si}$ waveguides were carried on at 1.3 and $1.55 \mu \mathrm{m}$ for both TE-TM polarizations. The schematic of the experimental setup is presented in Fig. 2. For our experiments, the SiGe waveguides were cleaved and then polished at the ends to form the waveguide surfaces. Insertion loss results from coupling loss due to the mismatch between the field profile of the input beam and guided mode, propagation loss of the guided mode, and Fresnel reflection loss at both endfaces. Assuming a normally incident beam the total Fresnel reflection loss was estimated to be 1.63 $\mathrm{dB} /$ facet.

The first light source is a pigtailed distributed feedback laser diode emitting at $1.3 \mu \mathrm{m}$ with an output power of 2 $\mathrm{mW}$, and the second light source is a pigtailed Fabry-Pérot laser diode operating at $1.55 \mu \mathrm{m}$ with a nominal power of $1.5 \mathrm{~mW}$ at the output of the fiber. An in-line fibered polar-

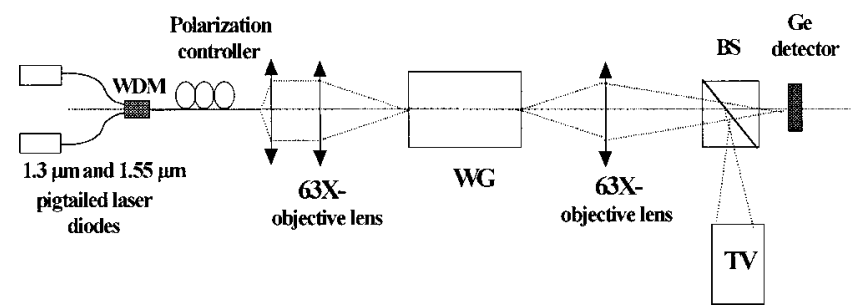

FIG. 2. Schematic of the experimental setup used for measuring the waveguide losses.

ization controller is used for adjusting the light polarization for both TE and TM guided mode excitation.

The fiber output is collimated and focused onto the waveguide input using two objective lenses. The waist of the focused beam is estimated using the input collimated beam waist before focusing and the focal length of the objective lens at about $1.07 \mu \mathrm{m}$ at $1.3 \mu \mathrm{m}$ and $1.27 \mu \mathrm{m}$ at $1.55 \mu \mathrm{m}$.

The output of the waveguide is imaged using an objective lens onto an infrared Ge detector. Using a beam splitter and an infrared video camera positioned at $90^{\circ}$ from the optical axis we could observe the image of the waveguide output and make the adjustments for optimum waveguide coupling.

Both input and output objective lenses are mounted on precision piezoelectric positioning stages that allow precise control of the alignment with the waveguide input-output. The waveguide mount is fixed on top of a precision four-axis waveguide manipulator that allows supplementary flexure rotations for an optimum alignment of the waveguide input with the input light beam.

Three different lengths of waveguides were used for the loss measurement. This is known generically as the cutback method. As the net propagation loss varies exponentially with the length of the waveguide, by using at least three different waveguide lengths we could eliminate the insertion and Fresnel losses (supposed the same for all waveguides) from the total loss measured. The averaged error due mainly to errors in measuring the length of the waveguides or different polishing quality from waveguide to waveguide is estimated at $\pm 0.3 \mathrm{~dB} / \mathrm{cm}$.

The main advantage of the experimental setup presented in Fig. 2 is the possibility of changing the polarization of the input light beam by using the in-line fiber polarizer. The mechanical positioning is not changed at the input and output ensuring a reliable way to measure the transmitted light for TE and TM polarization. Also, the wavelength is changed without modifying the positioning at the input or output, but just switching on the other laser source.

TABLE II. Experimental results for the propagation losses of the SiGe waveguides.

\begin{tabular}{lccccc}
\hline \hline Sample & $\begin{array}{c}\text { Guide } \\
\text { width }(\mu \mathrm{m})\end{array}$ & $\begin{array}{c}\text { Loss }(\mathrm{dB} / \mathrm{cm}) \\
1.3 \mu \mathrm{m}-\mathrm{TE} \\
( \pm 0.3 \mathrm{~dB} / \mathrm{cm})\end{array}$ & $\begin{array}{c}\text { Loss }(\mathrm{dB} / \mathrm{cm}) \\
1.3 \mu \mathrm{m}-\mathrm{TM} \\
( \pm 0.3 \mathrm{~dB} / \mathrm{cm})\end{array}$ & $\begin{array}{c}\text { Loss }(\mathrm{dB} / \mathrm{cm}) \\
1.55 \mu \mathrm{m}-\mathrm{TE} \\
( \pm 0.3 \mathrm{~dB} / \mathrm{cm})\end{array}$ & $\begin{array}{c}\text { Loss }(\mathrm{dB} / \mathrm{cm}) \\
1.55 \mu \mathrm{m}-\mathrm{TM} \\
( \pm 0.3 \mathrm{~dB} / \mathrm{cm})\end{array}$ \\
\hline 1427 & 15 & 2.1 & 2.2 & 2.3 & 2.2 \\
1427 & 25 & 2.9 & 2.7 & 2.6 & 2.7 \\
1427 & 300 & 2.7 & 2.8 & 3.0 & 3.2 \\
1430 & 15 & 1.7 & 1.8 & 2.2 & 2.4 \\
1430 & 20 & 2.2 & 2.4 & 2.5 & 3.3 \\
1430 & 300 & 2.5 & 2.5 & 2.9 & \\
\hline \hline
\end{tabular}


The results are reported in Table II. The best guiding performances are obtained for a sample with a $15 \mu \mathrm{m}$ guide width and $0.63 \mu \mathrm{m} \mathrm{Si}_{0.81} \mathrm{Ge}_{0.19}$ guiding layer thickness having $1.7 \mathrm{db} / \mathrm{cm}$ losses for TE polarization. It should be noted that according to Van de Walle, ${ }^{24}$ the band gap at this Ge concentration is about $1.01 \mathrm{eV}(4.2 \mathrm{~K})$. As estimated in Refs. 4 and 5 the residual absorption loss of a $\mathrm{SiGe}(19 \% \mathrm{Ge})$ guiding film would be at $1.3 \mu \mathrm{m}, 0.2 \mathrm{~dB} / \mathrm{cm}$ for a confinement factor of 1 . As can be seen from Table II, the TM guided wave losses are slightly larger than that of TE waves but the differences are relatively small. Another tendency that should be mentioned is the increase of the propagation losses with waveguide width.

We have reported high confinement $\mathrm{Si} / \mathrm{Si}_{0.98} \mathrm{Ge}_{0.02} / \mathrm{Si}_{1-x} \mathrm{Ge}_{x} / \mathrm{Si}$ low loss waveguides (minimum loss of only $1.7 \mathrm{db} / \mathrm{cm}$ ) grown by selective epitaxy, a method that allowed us an increase of the $\mathrm{Si}_{1-x} \mathrm{Ge}_{x}$ guiding film thickness over the plastic relaxation limit on large areas. The increased amount of $\mathrm{Ge}(19 \%)$ incorporated in these waveguides, and reduced $\mathrm{Si}$ cap layer are improvements from the previously reported $\mathrm{SiGe} / \mathrm{Si}$ waveguides where thick Si cap layers and reduced Ge concentrations $(<10 \%)$ are used. The loss of the $\mathrm{SiGe} / \mathrm{Si}$ waveguides is similar to those obtained by other authors ${ }^{25}$ (usually in the range of $2-3 \mathrm{~dB} / \mathrm{cm}$ ).

The waveguides offer a great potential for applications as waveguide LEDs to be integrated with waveguide modulators. ${ }^{6}$ Recently room-temperature operation of a vertical emitting $\mathrm{SiGe} / \mathrm{Si}$ LED, made by selective epitaxy, has been demonstrated ${ }^{3}$ and integration with $\mathrm{SiGe} / \mathrm{Si}$ waveguides and photodetectors present the opportunity for monolithic integrated photonic circuits.

The authors acknowledge T. Stoica for design of the masks. One of the authors (S.P.P) is grateful to the European
Community for financial support under Contract No. FMRX CT96-0029.

${ }^{1}$ R. D. Lareau, L. Friedman, and R. A. Soref, Electron. Lett. 26, 1653 (1990).

${ }^{2}$ B. Schüppert, J. Schmidchen, A. Splett, U. Fischer, T. Zinke, R. Moosburger, and K. Petermann, J. Lightwave Technol. LT-14, 2311 (1996).

${ }^{3}$ T. Stoica, L. Vescan, and M. Goryll, J. Appl. Phys. 83, 3367 (1998).

${ }^{4}$ A. Vonsovici, L. Vescan, R. Apetz, A. Koster, and K. Schmidt, IEEE Trans. Electron Devices 45, 538 (1998).

${ }^{5}$ A. Vonsovici, PhD thesis, Université Paris Sud, Orsay, France, 1996.

${ }^{6}$ A. Vonsovici, and L. Vescan, IEEE J. Sel. Top. Quantum Electron. 4, 1011 (1998).

${ }^{7}$ B. J. Li, G. Z. Li, and E. K. Liu, Infrared Phys. Technol. 39, 617 (1998).

${ }^{8}$ T. Stoica and L. Vescan, J. Cryst. Growth 131, 32 (1993).

${ }^{9}$ L. Vescan, Mater. Sci. Eng., B 28, 1 (1994).

${ }^{10}$ E. A. Fitzgerald, G. B. Pettit, R. E. Proano, and D. G. Ast, J. Appl. Phys. 65, 2220 (1989).

${ }^{11}$ L. Vescan, T. Stoica, M. Goryll, and K. Grimm, Mater. Sci. Eng., B 51, 166 (1998).

${ }^{12}$ R. A. Soref, F. Namavar, and J. P. Lorenzo, Opt. Lett. 15, 270 (1990).

${ }^{13}$ S. F. Pesarcik, G. V. Treyz, S. S. Iyer, and J. M. Halbout, Electron. Lett. 28, 159 (1990).

${ }^{14}$ A. Splett, J. Schmidtchen, B. Schüppert, and K. Petermann, Electron. Lett. 26, 1035 (1990).

${ }^{15}$ Y. M. Liu and P. R. Prucnal, Electron. Lett. 28, 1434 (1992).

${ }^{16}$ J. Schmidchen, B. Schüppert, and K. Petermann, J. Lightwave Technol. LT-12, 842 (1994).

${ }^{17}$ E. Lea and B. L. Weiss, Electron. Lett. 33, 292 (1997).

${ }^{18}$ Z. Yang, B. L. Weiss, G. Shao, and F. Namavar, J. Appl. Phys. 77, 2254 (1995).

${ }^{19}$ F. Namavar and R. A. Soref, J. Appl. Phys. 70, 3370 (1991).

${ }^{20}$ S. P. Pogossian, L. Vescan, and A. Vonsovici, J. Lightwave Technol. LT-16, 1851 (1998).

${ }^{21}$ H. Temkin, A. Antreasyan, N. A. Olsson, T. P. Pearsall, and J. C. Bean, Appl. Phys. Lett. 49, 809 (1986).

${ }^{22}$ S. P. Pogossian, L. Vescan, and A. Vonsovici, J. Opt. Soc. Am. A 16, 591 (1999).

${ }^{23}$ P. N. Robson and P. C. Kendall, Rib Waveguide Theory by the Spectral Index Method (Research Studies Press, England, 1990).

${ }^{24}$ C. G. Van de Walle and R. M. Martin, Phys. Rev. B 34, 5621 (1986).

${ }^{25}$ S. Janz, J-M. Baribeau, A. Delage, H. Lafontaine, S. Mailhot, R. L. Williams, D. X. Hu, D. M. Bruce, P. E. Jessop, and M. Robillard, IEEE J. Sel. Top. Quantum Electron. 4, 990 (1998). 